\title{
LSCS audit in a tertiary care center in Mumbai: to study indications and risk factors in LSCS and it's effect on early peri-natal morbidity and mortality rate
}

\author{
Rajshree Dayanand Katke*, Ashish N. Zarariya, Pranay V. Desai
}

\begin{abstract}
Department of Obstetrics \& Gynaecology, Cama \& Albless Hospital, Grant Govt. Medical College, Mumbai,
\end{abstract} Maharashtra, India

Received: 7 September 2014

Revised: 2 October 2014

Accepted: 3 October 2014

\section{*Correspondence:}

Dr. Rajshree Dayanand Katke,

E-mail: drrajshrikatke@gmail.com

Copyright: $($ ) the author(s), publisher and licensee Medip Academy. This is an open-access article distributed under the terms of the Creative Commons Attribution Non-Commercial License, which permits unrestricted non-commercial use, distribution, and reproduction in any medium, provided the original work is properly cited.

\section{ABSTRACT}

Background: Caesarean section has become a relatively safer and so common procedure in the practice of modern obstetrics. Audit plays an important role in the analysis of changing trends in caesarean delivery. The present retrospective analytical study attempts to critically analyze 474 cases of caesarean deliveries performed in tertiary hospital over a span of six months with an aim to identify the indications and risk factors involved in early peri-natal morbidity and mortality.

Methods: The Cama and Albless hospital is a tertiary care center located in South Mumbai, which cares for over 3000 deliveries per year. In the present retrospective analytical study, all cases of caesarean delivery from August 2013 to January 2014 were analyzed regarding the indication, associated risks factors, and all NICU admissions were studied. The decision to perform a caesarean section in each of these patients was made by a consultant on duty in consultation with the unit head telephonically. The primary objective of the study was to do LSCS audit with the secondary objective to analyse relationship of early peri-natal morbidity with indication of LSCS and risk factors associated.

Results: In the present study we found that the overall incidence of LSCS is $25.7 \%$, incidence of primary LSCS is $23.1 \%$, incidence of LSCS in Referred cases is $61.7 \%$. So overall high incidence of LSCS is justified as our's is a tertiary care referral unit. $3.5 \%$ of total LSCS cases were elderly gravidas and teenage pregnancies each. In our study, $11.8 \%$ and $3.5 \%$ patients were less than 37 weeks and 34 weeks respectively. However $30.6 \%$ of NICU admissions were due to low birth weight. So IUGR in near term patients is an important morbid factor. Previous LSCS was the leading indication in $35.2 \%$ of cases followed by foetal distress in $14.9 \%$ of cases and Previous 2 LSCS $10.5 \%$. Two important relative indications we found were Previous 1 LSCS and PIH contributing for nearly half of the total cases. Average duration of surgery was 86 minutes in our study and average stay in hospital was 9 days. In our study early perinatal mortality was $1.6 \%$ and morbidity in the form of NICU admissions was $20.8 \%$. Most common cause for NICU admission was LBW followed by Respiratory distress. After comparing high risks factors and indications with NICU admissions we found highest morbidity in neonates who underwent LSCS for fetal distress, multiple pregnancy and premature rupture of membranes.

Conclusions: Individualization of the indication and careful evaluation can help us limiting early peri-natal morbidity and mortality. Obstetric audits in the institution, following standardized guidelines and practice of evidenced-based medicine will help us a lot in reducing the peri-natal morbidity and mortality.

Keywords: LSCS, Indications, Risk factors, Perinatal morbidity and mortality 


\section{INTRODUCTION}

The advent of better anaesthesia, availability of improvised surgical techniques and prophylactic antibiotics have made caesarean section a relatively safer and a common procedure. The decision whether to perform a caesarean section or not is based on the individualized judgement of the obstetrician and the hospital where caesarean would be performed. Economic factors and fear of litigation are other considerations which may indirectly influence such decisions. Audit plays an important role in the analysis of changing trends in caesarean delivery rates, the needs and benefits of such changes and to modify the obstetricians towards the use of caesarean delivery. The present retrospective analytical study attempts to critically analyze 474 cases of caesarean deliveries performed in tertiary hospital over a span of six months with an aim to identify the indications and risk factors involved in early peri-natal morbidity and mortality.

\section{METHODS}

The Cama and Albless hospital is a tertiary care center located in South Mumbai, which cares for over 3000 deliveries per year. In the present retrospective analytical study, all cases of caesarean delivery from $1^{\text {st }}$ August 2013 to $31^{\text {st }}$ January 2014 were analyzed regarding the indications, associated risks factors, and all NICU admissions were studied. The decision to perform a caesarean section in each of these patients was made by a consultant on duty in consultation with the unit head telephonically. The primary objective of the study was to do LSCS audit with the secondary objective to analyse relationship of early peri-natal morbidity with indication of LSCS and risk factors associated.

\section{RESULTS}

We carried LSCS audit in the above period, analysed excel sheet and observed following parameters.

1) Incidence

2) Age

3) Parity

4) Booked status

5) Gestational age

6) Indications of LSCS

7) High risk factors associated with indications of LSCS

8) Duration of surgery
9) Intra-operative complications

10) Neonatal outcome

11) Birth weight in NICU

12) Early Perinatal morbidity and mortality

13) Relation of indications and high risk factors with neonatal morbidity

14) Total hospital stay in days

15) Post-operative complications

Our observations are as follows:

\section{Incidence}

We had total 1844 number of deliveries from $1^{\text {st }}$ August 2013 to $31^{\text {st }}$ January 2014. Out of which 474 were LSCS. So the overall incidence of LSCS is $25.7 \%$. We had total number of 79 cases who were not booked with our institute and underwent LSCS. Total number of referred cases during this 6 month period were 128 so the incidence of LSCS in Referred cases is $61.7 \%$ so $25.7 \%$ incidence is justified, us being a tertiary care center. Total number of primigravidas delivered in this period were 657 out of which 505 were vaginal deliveries and 152 were LSCS.

So incidence of primary LSCS (LSCS in primigravida) is $23.1 \%$.

\section{Age}

$3.5 \%$ of total LSCS cases were elderly gravidas (35 and above). Similarly $3.5 \%$ of total LSCS patients were teenage pregnancies.

\section{Parity}

$32 \%$ patients were primipara and only $1 \%$ were grand multipara (4 and above).

\section{Booked status}

$0.6 \%$ patients were unbooked cases and $15.4 \%$ patients were referred from private practitioner at Bhiwandi (distant suburb) and $0.6 \%$ from other government hospitals. So total number of $16.6 \%$ patients who underwent LSCS in our study were registered with us for the first time.

\section{Gestational age}

$11.8 \%$ (56) patients were less than 37 weeks maturity. Out of these $11.8 \%$ patients, total $3.5 \%$ (17) patients were 
less than 34 weeks maturity. Total $2.1 \%$ patients were post-dated pregnancy (>42 weeks).

\section{Indications of LSCS}

Table 1: Indications of LSCS (N=474).

\begin{tabular}{|lll|}
\hline Indications & Number & Percentage \\
\hline Previous 1 LSCS & 167 & 35.23 \\
\hline Fetal distress & 71 & 14.97 \\
\hline Previous 2 LSCS & 50 & 10.54 \\
\hline PIH & 42 & 8.86 \\
\hline Malpresentations & 29 & 6.11 \\
\hline Failure of induction & 24 & 5.06 \\
\hline CPD & 22 & 4.64 \\
\hline Labour abnormalities & 21 & 4.43 \\
\hline APH & 12 & 2.53 \\
\hline Multiple pregnancies & 10 & 2.11 \\
\hline Oligohydramnios & 9 & 1.89 \\
\hline PROM & 9 & 1.89 \\
\hline IUGR & 3 & 0.63 \\
\hline Post-datism & 3 & 0.63 \\
\hline Medical disorders & 2 & 0.42 \\
\hline
\end{tabular}

The main indications of caesarean delivery are shown in Table 1. Previous LSCS, was the leading cause in $35.2 \%$ of cases. This was followed by foetal distress in $14.9 \%$ of cases and previous 2 LSCS $10.5 \%$.

Most number of indications were relative indications. Two important relative indications and associated risk factors we studied were A) Previous 1 LSCCS and B) PIH.

Table 2A: High risk factors associated with prev LSCS (N=167).

\begin{tabular}{|lll|}
\hline High risk factors & Number & Percentage \\
\hline Scar tenderness & 55 & 32.9 \\
\hline In labour with floating head & 50 & 29.9 \\
\hline CPD & 13 & 7.7 \\
\hline Fetal distress & 13 & 7.7 \\
\hline Malpresentations & 7 & 4.1 \\
\hline Post-datism & 7 & 4.1 \\
\hline PROM & 7 & 4.1 \\
\hline Failure of induction & 5 & 2.9 \\
\hline PIH & 4 & 2.3 \\
\hline Oligohydramnios & 3 & 1.7 \\
\hline BOH & 1 & 0.5 \\
\hline Twins & 1 & 0.5 \\
\hline Non progress of labour & 1 & 0.5 \\
\hline
\end{tabular}

Table 2A shows the number and percentage of repeat caesarean deliveries in cases of previous caesarean deliveries. Scar tenderness and floating head in labour accounted for $>75 \%$ of cases.
Table 2B: PIH and its association with indication of LSCS $(\mathrm{N}=42)$.

\begin{tabular}{|lll|}
\hline High risk factors & Number & Percentage \\
\hline None & 11 & 26.1 \\
\hline Failure of induction & 5 & 11.9 \\
\hline Labour abnormalities & 4 & 9.5 \\
\hline Fetal distress & 3 & 7.1 \\
\hline Twin gestation & 3 & 7.1 \\
\hline APH & 3 & 7.1 \\
\hline CPD & 2 & 4.7 \\
\hline IUGR & 2 & 4.7 \\
\hline Eclampsia & 2 & 4.7 \\
\hline Malpresentation & 2 & 4.7 \\
\hline Oligohydramnios & 1 & 2.3 \\
\hline Thrombocytopenia & 1 & 2.3 \\
\hline
\end{tabular}

Table 2B shows number and percentage of caesarean deliveries in PIH cases.

PIH per se is not an indication for LSCS but in our study we found 11 cases (26.1\%) underwent LSCS primarily for PIH.

\section{Duration of surgery}

Average time taken from taking the Patient to OT table to taking her to recovery room was 86 minutes.

\section{Intra-operative complications}

In our study $0.8 \%$ of patients underwent PPH. Only 1 $(0.2 \%)$ patient required systematic devascularisation of uterus for PPH.

None required B-Lynch suture and or Obstetric Hysterectomy. No other major intra-operative complication encountered.

\section{Neonatal outcome}

Table 3: Neonatal outcome $(\mathrm{N}=474)$.

\begin{tabular}{|lll|}
\hline Outcome & Number & Percentage \\
\hline NICU admission at birth & 56 & 11.8 \\
\hline FSB & 0 & 0 \\
\hline MSB & 2 & 0.4 \\
\hline $\begin{array}{l}\text { NICU admission during } \\
\text { hospital stay }\end{array}$ & 43 & 9 \\
\hline Early neonatal death & 6 & 1.3 \\
\hline Healthy neonates & 367 & 77.5 \\
\hline
\end{tabular}

Table 3 shows neonatal outcome in LSCS. 1.6\% was early perinatal mortality (MSB with early neonatal death). Total NICU admission was $20.8 \%$, out of these $11.8 \%$ were immediately shifted from Operation Theatre and rest $9 \%$ were shifted from Post-Operative Ward to NICU. 


\section{Birth weight in NICU}

Table 4 shows number and percentages of neonates admitted in NICU according to their birth weight. ELBW were $12.8 \%$.Total $50.7 \%$ of NICU admission were LBW. Total number of macrosomic babies were $3.9 \%$ When we compared gestational age data with birth weight and NICU admission, we found that out of 17 premature neonates ( $<34$ weeks), all were admitted for weight gain and rest $35 \mathrm{LBW}$ were small for gestational age. High number of small for gestational age neonates may be because of poor antenatal care.

Table 4: Birth weight in NICU (N=99).

\begin{tabular}{|lll|}
\hline Birth weight & Number & Percentage \\
\hline $1-1.5$ & 13 & 13.1 \\
\hline$>1.5-2.0$ & 20 & 20.2 \\
\hline$>2.0-2.5$ & 19 & 19.2 \\
\hline$>2.5-3.0$ & 17 & 17.2 \\
\hline$>3.0-3.5$ & 22 & 22.2 \\
\hline$>3.5-4.0$ & 7 & 7.1 \\
\hline$>4.0$ & 4 & 4 \\
\hline
\end{tabular}

\section{Early perinatal morbidity and mortality}

Table 5 shows the number and percentage of NICU admissions and mortality in all the cases of LSCS. Most common cause for NICU admission was LBW as seen in
$30.6 \%$ cases. Respiratory distress accounted for $16.8 \%$ cases while large for gestational age and sepsis accounted for $13 \%$ cases and $8.9 \%$ respectively. Congenital anomalies were present in $7.9 \%$ cases. Percentages of babies admitted in NICU for jaundice were 6.9\%. $1.98 \%$ were macerated still born although out of total 99 NICU admissions 6 neonatal deaths had occurred. So overall perinatal mortality was approximately $6 \%$ in all NICU admissions in our study.

Table 5: Early perinatal morbidity and mortality $(\mathrm{N}=101)$.

\begin{tabular}{|lll|}
\hline Causes & Numbers & Percentage \\
\hline LBW & 31 & 30.6 \\
\hline RD & 24 & 23.76 \\
\hline LGA (NON-DM) & 9 & 8.91 \\
\hline LGA (DM) & 4 & 3.96 \\
\hline Sepsis & 9 & 8.91 \\
\hline Cong anomalies & 8 & 7.92 \\
\hline Jaundice & 7 & 6.93 \\
\hline Prom >18 hours & 4 & 3.96 \\
\hline Observation & 3 & 2.97 \\
\hline MSB & 2 & 1.98 \\
\hline Total & 101 & 100 \\
\hline
\end{tabular}

Relation of indications and high risk factors with neonatal morbidity

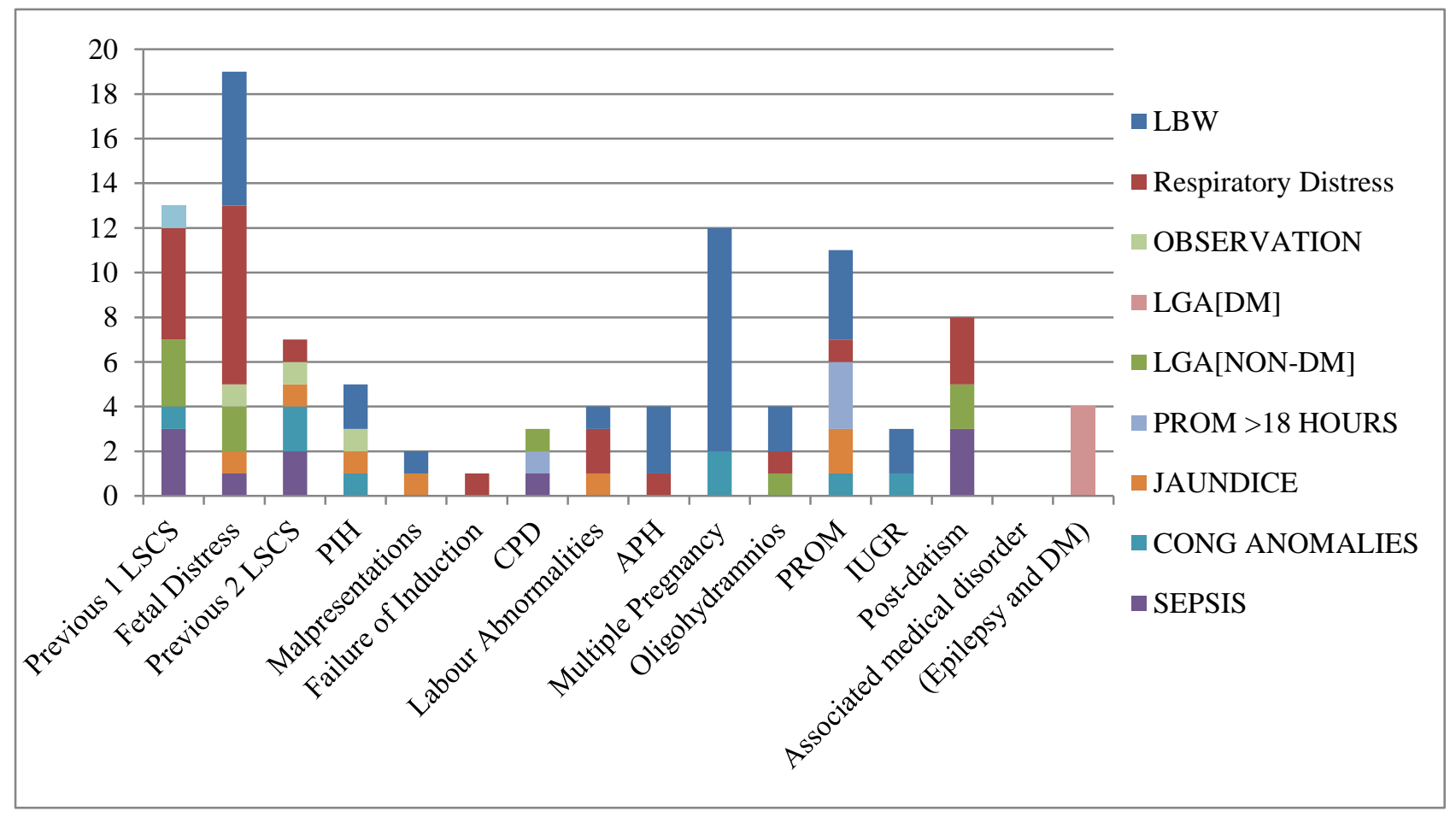

Figure 1: Relation of indications and high risk factors with neonatal morbidity (N=99). 
As per Figure 1 highest morbidity is found in neonates who underwent LSCS for fetal distress. As previous LSCS cases have outnumbered the other indications neonatal morbidity in this group is understandable. Multiple pregnancy, premature rupture of membranes, postdatism group has high neonatal morbidity.

\section{Post-operative complications}

Post-operative paralytic ileus was uncommon in our study. $0.8 \%$ of patients had febrile morbidity, $1.4 \%$ patients suffered from wound dehiscence requiring resuturing.

\section{Stay in hospital}

Average stay in hospital was 9 days.

\section{DISCUSSION}

There has been a steady increase in the rate of caesarean section in both developed and developing countries. Although the WHO recommends that there is no justification to increase a caesarean rate in excess of 10 to $15 \%$, it may be difficult to contain the rates in tertiary institutes, catering to a large population of transferred cases. ${ }^{1}$

In our study the most common indication for LSCS was Previous LSCS (35.23\%) followed by fetal distress (14.97\%), and previous 2 LSCS (10.54\%). PIH accounted for $8.86 \%$ of cases while malpresentations for $6.11 \%$ of cases. APH accounted for $2.53 \%$ of cases. The least common being postdatism and IUGR.

In a study of 614 cases conducted in Pakistan at Nawaz Sharif social security hospital at Lahore showed similar results with previous LSCS being the most common indication accounting for $56.3 \%$ of cases followed by fetal distress $(17.5 \%)$. Placental abruption was the least common cause of LSCS accounting for $0.9 \% .^{2}$ Similar study done in Mymensingh medical college the most common indication for LSCS was previous LSCS (16\%), followed by fetal distress (15\%), and obstructed labour $(14 \%)$ and Pre-eclampsia and eclampsia for $12 \% .^{3}$

Foetal distress was the next leading indication for performance of a caesarean section in the present study series. Foetal distress refers to foetal hypoxia, but often no efforts are taken to document this condition which would be desirable for medicolegal purposes later. Also a significant rise in caesarean section could be attributed to electronic foetal monitoring. A study by Levens et al. published in the New England journal of medicine confirms, higher caesarean section rates for foetal distress with no significant difference in the perinatal mortality rates in the caesarean versus vaginal route of delivery. ${ }^{4}$

In case of NICU admissions, there were total of 99 admissions out of 474 LSCS cases. Most common cause for NICU admission was LBW accounting for $30.6 \%$ cases followed by respiratory distress accounting for $27.3 \%$ cases. LGA babies of non-Diabetic mothers and sepsis in babies each accounted for $8.9 \%$ of cases. Early perinatal mortality was $7.9 \%$; similarly in Mymensingh study $1 \%$ was still born and $7 \%$ had early neonatal death. A study conducted in 3 countries in Sub-Saharan Africa from August 12010 to January 312011 comprising of 1276 cases showed 1 in every $7 \mathrm{C}$-sections resulted in early neonatal death. This high rate may reflect inadequate labour management and the late transfer of patients from home or a health center to the hospital.

When we compared early perinatal morbidity with indication and high risk factor, we found neonatal morbidity is high in fetal distress, PROM, PIH, postdatism and multiple pregnancy group so we suggest early intervention and effective management in these 5 groups can help us in reducing perinatal morbidity and mortality.

\section{CONCLUSION}

Previous caesarean section was the leading indication for a caesarean delivery in the study group. Therefore a careful individualization of every case, meticulous clinical examination and use of intensive intrapartum foetomaternal surveillance could probably reduce the rates of caesarean section. ${ }^{5}$

In conclusion, it would be ideal to initiate obstetric audits by interdepartmental meetings, to assess the intrinsic role of caesarean section in influencing the foetomaternal outcome.precise interpretation of fetal heart rate tracing and use of fetal $\mathrm{pH}$ might be effective in reducing caesarean section rate. ${ }^{6}$ Use of standardized management guidelines and practice of evidence based obstetrics would definitely go a long way in balancing the rates of caesarean section.

Funding: No funding sources Conflict of interest: None declared

Ethical approval: The study was approved by the institutional ethics committee

\section{REFERENCES}

1. Asha Oumachigui. Changing Trends in Caesarean section. Obstet Gynaecol Today. 2002;7:1-5.

2. Saima Rafique, Gul e Raana. Changing trends in caesarean section rate and indications. Pak J Surg. 2012;28(1):60-4.

3. Khairun Nahar. Indications of caesarean section: study of 100 cases in Mymensingh medical college hospital. J Shaheed Suhrawardy Med Coll. 2009 Dec;1(1):6-10.

4. Levens KJ, Cunningham FG, Nelson S, Roark M, Williams ML, Guzick D, et al. A prospective comparison of selective and universal electronic 
foetal monitoring in 34, 995 pregnancies. N Engl J Med. 1986;315:615-9.

5. ACOG Committee Opinion. Vaginal delivery after caesarean birth. Vol. No. 143 - Oct 1994. Committee on obstetric practice. Int J Obstet Gynaecol. 1995;48:127.

6. Chanthasenanont A, Pongrojpaw D. Indications for Caesarean section at Thammasat University hospital. J Med Assoc Thai. 2007;90:1733-7.
DOI: $10.5455 / 2320-1770 . i j r c o g 20141217$

Cite this article as: Katke RD, Zarariya AN, Desai PV. LSCS audit in a tertiary care center in Mumbai: to study indications and risk factors in LSCS and it's effect on early peri-natal morbidity and mortality rate. Int $\mathrm{J}$ Reprod Contracept Obstet Gynecol 2014;3:963-8. 